\title{
PATENT DUCTUS ARTERIOSUS
}

\author{
BY \\ D. C. MUIR, M.D., M.R.C.P., \\ and \\ J. W. BROWN, M.D., M.R.C.P.
}

The impression that has been gathered from a perusal of the available literature is that a patent ductus arteriosus as a sole abnormality is comparatively rare. In Abbott's ${ }^{1}$ coliected series of 850 cases there were but 73, and in Laubry and Pezzi's ${ }^{2}$ well-known work the lesion is said to be rare. Recently Perry ${ }^{3}$ in a review of congenital heart lesions in Bristol school children found, amongst 121 cases, 8 instances ( 6 per cent.) of patent ductus arteriosus. In our own series of 88 cases of congenital heart disease occurring for the most part in school children, we find no less than 20 cases or 23 per cent. of the total to have signs which suggest a patent ductus arteriosus as the sole abnormality.

Much has been written with regard to this abnormality, for where it has been discovered it has usually been well studied. Perhaps it is the most completely investigated lesion in congenital cardiac pathology.

Symptoms.-It has been said that subjects with a patent ductus arteriosus are generally slightly built, somewhat under-developed and anæmic. A wax-like pallor has been recorded as present and characteristic, and this has been attributed to a hypoplasia of the aorta with consequent depletion of the arterial system. All are agreed that there are rarely any symptoms. Such symptoms as have occurred are those of hyperpnœa on exertion and palpitation. Cyanosis is usually absent, and when it has occurred it has been in relation to exertion or to pulmonary infection, and thus in the latter case follows the lines of the ' cyanose tardive' described by the French. Epileptiform convulsions may occur in patients with congenital heart disease with lesions that permit venous shunting. This is especially so in infants where such an act as sucking raises the pressure in the pulmonary artery above that in the aorta. In 2 cases of patent ductus arteriosus recorded by Shirley Smith $^{4}$ such fits occurred and were associated with cyanosis. More recently Leech $^{5}$ has collected similar cases.

Physical signs.-The characteristic physical sign is a long rough murmur best heard in the first and second left interspaces, though sometimes a little lower, close to the sternum. The character of the murmur varies with the age of the patient. In infancy when the patent duct is a straight tube the murmur may be indistinguishable from that caused by a septal defect. When the pulmonary artery becomes dilated in later childhood the bruit takes on its 
continuous character. At just what age this may occur it is difficult to say. The murmur may be systolic in time but more often it is continuous, being best heard in systole, when it is reinforced, and waning in diastole. This continuous murmur, which was first described by Gibson ${ }^{6}$, is absolutely pathognomonic, and has been variously described as continuous, churning, humming, rolling thunder, machinery, tunnel-like or sawing. It is usually best heard in the second left intercostal space close to the sternum: occasionally better over the third left interspace. The murmur increases on inspiration and sometimes the continuous element of the murmur is best appreciated with the subject erect. The systolic element may be heard at the apex, towards the left axilla, along the left border of the sternum, and under the clavicle. At times it may be heard in the left carotid, and not infrequently in the left mid-and infra-scapular region. In the latter situation it has been attributed to a narrowing of the aorta at the site of the ductus. A diastolic bruit may be present and heard along the left border of the sternum. This has been attributed by Laubry and Pezzi ${ }^{2}$ to dilatation of the pulmonary artery, or it may be due to aortic incompetence. The possibility that aortic reflux, if present, may be the result of infection of the aortic valves should not be forgotten. In cases where the communication is large there is lively arterial pulsation in the neck accompanied by a low diastolic pressure and this may lead to further confusion with aortic regurgitation. The pulmonary second sound is accentuated or reduplicated. This sign may be easily overlooked unless it is sought for below the site of maximum intensity of the murmur. Although this sign has a certain value in the differential diagnosis it must be interpreted with caution, as an accentuated pulmonary second sound is a common finding in children. Accompanying the murmur may be a thrill which is systolic, continuous or diastolic in time, and may be diffuse, or localized to the base, with maximum intensity in the second left interspace, or at a site corresponding with the maximum intensity of the bruit. In Abbott's 84 collected cases it was present in 23; in 9 continuous, in 11 systolic and in 3 diastolic. $\mathbf{A}$ systolic thrill would appear to be more frequent than a continuous thrill. Its absence has been interpreted as indicating that the communication is large. Dilatation of the pulmonary artery is almost invariably present, because the flow of blood is from the aorta into the pulmonary artery, although under certain conditions the flow may be in an opposite direction (Holman ${ }^{8}$ ). It is shown by Gerhardt's dullness, a ribbon-like area of dullness in the second and third left spaces close to the sternum. This is not always clinically appreciable in children, but can almost always be detected in adults. Confirmation may be obtained by the use of the X-rays, when the cardiac silhouette characteristic of the lesion may be discovered. Gerhardt in addition described visible systolic pulsation in the second left space, but this sign cannot always be elicited despite the presence of dullness.

Certain arterial phenomena have been recorded. There is no change in the systolic pressure but the diastolic pressure may be lowered, giving rise to an arterial dance, and confusion with aortic incompetence. The pulses 
may be unequal, the left being smaller than the right and delayed in comparison with the right. A difference in amplitude between the femoral and radial pulses has been emphasized by Laubry ${ }^{7}$, and when this is present it is significative of some slight stenosis of the aorta, perhaps insufficient to cause a dorsal systolic bruit. These arterial changes are best detected by polygraphic methods, and when present they are striking.

The pulsus paradoxus, said to occur in this condition (F. Franck), is inconstant and not a striking feature in most recorded cases. The blood pressure may be lower in the left arm than in the right. Paralysis of the left vocal cord due to pressure on the recurrent nerve is a rare, but valuable sign.

Radiological examination.-This is always of the greatest importance in assisting the diagnosis and in confirmation of clinical findings. The heart should be observed with rays as nearly parallel as possible, and the right oblique view should be used in addition to a frontal examination. Sometimes there is apparently no change in the cardiac silhouette in the frontal position in children, but in the right oblique position dilatation of the pulmonary artery can be seen. Sometimes on the screen the appearances, despite obvious physical signs, are normal. More often there is alteration in the pulmonary arc of the left cardiac border, the middle arc being prominent, rounded, and bulging, and in some cases almost hemispherical. This is even better seen in the oblique view, and corresponds to the dilatation of the trunk of the pulmonary artery which is a common but not essential accompaniment of a patent ductus arteriosus. In cases where the pulmonary arc is enlarged there is also enlargement of the right cavities of the heart. This prominence of the pulmonary arc has been called the X-ray cap of Zinn. There is rarely any increase in the left side of the heart unless there is some added complication such as co-arctation of the aorta or aortic reflux.

Electrocardiographic results.-These are most frequently physiological, although there may be increased amplitude of the QRS complexes. There is nothing in the electrocardiogram that is in any way diagnostic of the condition.

Diagnosis.-As criteria in diagnosis we have accepted the following physical signs as being the most essential:-

1. The presence of a continuous or machinery murmur, maximum in the second left interspace close to the sternum.

2. A long rather rough systolic bruit heard in the upper part of the left chest with maximum intensity in the second left interspace, with conservation, accentuation, or reduplication of the pulmonary second sound.

3. Gerhardt's ribbon dullness.

4. Radiological evidence of dilatation of the pulmonary artery.

5. Comparative absence of symptoms. 
The association of any three of the above in a patient we consider to be sufficient for diagnosis. The presence of a machinery murmur is of itself sufficient for diagnosis.

\section{Authors' series of cases.}

The 20 cases outlined and analyzed below (see Appendix) have for the most part occurred either in school children or in hospital practice. In the examination of these cases our routine has been to measure height and weight, proceed to the clinical examination, and then subsequently examine them radiologically with a standard seven-foot technique. Certain of the patients, if not too young, have been investigated with the polygraph, and a few with the electrocardiograph.

Of the 20 cases in this series 7 are males and 13 are females. The youngest is 5 and the oldest 21 .

As regards the mode of the initial discovery of a cardiac lesion, 15 of the patients learnt of its existence at the routine school examination, and 5 had the lesion discovered during the course of some infectious disease such as measles (2), pneumonia (1), or influenza (2). Three of the patients have known of the existence of their lesion for 9 years or longer.

Physical development.-As regards physical development the patients were compared with average tables of school children of corresponding age. Contrary to expectation 6 were of average development, 9 were definitely above the average, and only 5 were under average. The slender gracile build was conspicuously absent. One only appeared definitely anæmic.

Symptoms.- Fifteen of the cases were completely free of symptoms and devoid of all complaints at the time of examination. Two of the patients complained of pain round the heart, one a child aged 12, and the other a male aged 21. In the latter case the pain was substernal, radiated to the left shoulder, scapula, and down the inner side of the left arm. It was provoked by exertion and disappeared with rest. When the pain subsided a sensation of warmth supervened in the areas in which pain had been felt. There was no electrocardiographic abnormality. Another patient aged 12 complained of vague chest pains. In 2 cases a neurosis was present and this had been fostered by an incorrect diagnosis in the first instance and by parental anxiety and complete restriction of all physical activity. Tachycardia on slight exertion was present in 1 case. Signs of infective endocarditis were present in 1 case. Dyspnœa and palpitation on exertion were complained of in the 2 elder patients. Transient cyanosis occurred with infection in 3 cases. In 1 case, two fits in which the child had been blue, had preceded the discovery of the lesion by 2 years, and in yet another, fits had occurred in earliest infancy. If one fact emerges from the study of these cases it is the relative absence of symptoms.

Physical signs.-In no case was the heart greatly enlarged on clinical examination, nor was dullness detected to the right of the sternum. Gerhardt's ribbon dullness was found to be present in 7 patients, the youngest 
being a female of 5 years of age. A systolic thrill was found in 12 cases, i.e., 60 per cent. In 1 case it was felt diffusely over the præcordia; in the others it was felt over the upper part of the left side of the chest with maximum intensity in the second left interspace close to the sternum. There appeared to be no correlation between the existence of a thrill and a machinery murmur. A thrill and a continuous murmur were present in 7 cases in the series and a systolic bruit with a thrill in 2 cases. A continuous or machinery bruit was found 12 times (60 per cent.) in the series. In 1 case it was maximum in the first left interspace, and in 11 in the second left interspace close to the sternum. In 6 of the cases the continuous element of the bruit was appreciable as low as the third left interspace and the fourth costal cartilage.

From our investigation it would appear that no definite statement can be made as to the age at which a machinery murmur can first be heard. It was heard in one case at the age of 5 , and was accompanied by notable prominence of the middle arc in the frontal position. On the other hand a machinery murmur may be present at any early age without notable prominence of the pulmonary arc, such dilatation of the pulmonary artery as is present being detected only on examination in the oblique position. Further work is required amongst school children in order to discover the age at which the systolic bruit becomes continuous. The association of a systolic bruit and thrill in the second left space, with absence of cyanosis and with an accentuated pulmonary second sound, should always lead to suspicion that a patent ductus is present. In this connexion it may be reaalled that occasionally a continuous murmur is best recognized when the subject is erect.

A diastolic murmur was heard in 3 cases along the left border of the sternum. In none of these cases was there any history of rheumatic infection. One case at autopsy was found to have recent vegetations on the aortic valve as part of an infective endocarditis ${ }^{10}$. In all cases the pulmonary second sound was well heard and in 4 of them it was reduplicated.

X-ray examination.-(See illustrations in appendix, pp. 299 and 301).We have found the $\mathrm{X}$-ray examination of considerable value in confirmation of the diagnosis of this condition. Perry ${ }^{3}$ was of the opinion that X-ray examination was of little value in the elucidation of congenital cardiac pathology, and in particular quotes Lincoln and Spilman ${ }^{9}$ as stating that the pulmonary arc of the left cardiac border was enlarged and prominent in as many as 21.3 per cent. of normal children. In Perry's own series of congenital heart cases the pulmonary arc was prominent in 26.8 per cent.

In 16 of our 20 cases the pulmonary arc was prominent in the frontal position and a machinery bruit was associated with 10 of these. A machinery bruit was present without notable prominence of the pulmonary arc in 1 case. In the remaining cases the diagnosis rested on purely clinical grounds.

In all cases careful search was made for notching of the under surfaces of the ribs significative of a coarctation of the aorta which was considered as a possible associated defect likely to escape notice, 
Electrocardiogram.-An electrocardiogram taken in $\mathbf{5}$ cases was physiological. There was no abnormal axis deviation. In 3 cases the QRS complexes were tall in leads II and III and in 1 case low voltage was present in all 3 leads.

Differential diagnosis.-A patent ductus arteriosus has to be diagnosed from other congenital defects, from conditions in which a hæmic or functional murmur is present, and from rheumatic heart disease.

In the presence of a continuous murmur, localized in the second left space, there should be no difficulty as this bruit is pathognomonic. In those cases in which a harsh systolic bruit is maximum in the second left space with absence of cyanosis and clubbing, the presence of a well-heard or accentuated or reduplicated pulmonary second sound will serve to differentiate the condition from pulmonary stenosis, for in this latter condition the pulmonary second sound is weakened or absent, although an accentuated second sound has been recorded in pulmonary stenosis by Eakin ${ }^{11}$.

In cases in which there is an inter-ventricular septal defect, the murmur is generally loudest in the third and fourth left spaces close to the sternum, and is heard with diminishing intensity towards the apex and left clavicle.

In general it may be said that the bruit in congenital heart disease is remarkably constant in localization and in character. Some of the children have been observed over years without any marked alteration in the clinical signs.

Hæmic bruits are as a rule blowing in character and are susceptible to change in the position of the subject, and vary with the phase of respiration.

Differentiation from rheumatic heart disease rarely presents any great difficulty. The bruits of rheumatic valvular disease have a different localization, and are associated with modifications in the cardiac sounds, and frequently with enlargement of the heart.

The history of the case is often of the utmost value in diagnosis. A history of rheumatic infection may be given. Of great importance in a difficult case is the history of the discovery of a cardiac lesion. If there has been knowledge of a cardiac lesion since early infancy or since below the age of 5 , it is strong evidence in favour of a congenital abnormality, as the incidence of rheumatic heart disease is mainly after 5 years of age.

Contrary to the opinion expressed by Perry" we have found the $\mathrm{X}$-rays of considerable value in diagnosis. The radiological features of a patent ductus arteriosus are sufficiently definite to be of value in the differentiation from other congenital conditions. Evidence may not a!ways be striking in very young children but it is frequently so in older subjects. It is particularly useful in the confirmation of such a sign as Gerhardt's dullness. Other heart conditions in children, such as pulmonary stenosis, and particularly the tetralogy of Fallot, have rather characteristic pictures which are helpful in differential diagnosis. Mitral stenosis can be readily recognized in the oblique position with barium in the œsophagus. 


\section{Conclusions.}

1. Twenty cases are presented in which clinical and radiological examination have suggested a diagnosis of a patent ductus arteriosus.

2. Certain criteria necessary to establish a diagnosis have been suggested. A combination of any three of the following signs are considered as adequate for a diagnosis.

a. The presence of a continuous or machinery bruit in the second left space.

b. The presence of a long rough systolic bruit with maximum intensity in the second left interspace, with conservation, accentuation, or reduplication of the pulmonary second sound.

c. Gerhardt's ribbon dullness.

d. Radiological evidence of dilatation of the trunk of the pulmonary artery.

e. Comparative absence of symptoms.

3. No direct relationship can be established between the presence of a machinery murmur and thrill, or between any degree of dilatation of the pulmonary artery and a machinery bruit.

4. In cases that exhibit Gerhardt's dullness, radiological confirmation is always forthcoming.

5. Radiographic examination has a definite value in the differentiation of this condition from some other forms of heart disease in children.

6. Investigation is still necessary to establish the average age and the conditions under which a continuous murmur may appear. This can probably be best accomplished in a heart clinic maintained in connexion with a well organized school medical service.

Our thanks are due to Drs. Morrison and Watt of the Hull School Medical Service, and to Dr. Southey of the Grimsby School Medical Service, for valuable help given in segregating these children at school medical examinations; and to Dr. Bannen and Mr. S. Dolby for the radiograms. 


\section{APPENDIX.}

\section{Summary of cases.}

Case 1 (Fig. 1).-Female, aged 11, presents no symptoms. Lesion has been known of for seven years. Undersized. Machinery bruit heard in the second left space. Systolic thrill in the left infraclavicular region. Systolic bruit audible along the left border of the sternum and at the apex. Pulmonary second sound well heard. $\mathrm{X}$-ray evidence positive.

Case 2 (Fig. 2).-Female, aged 9. No symptoms, and lesion known of for four years since its detection at the routine school examination. Machinery bruit in the first left space. Systolic bruit heard at the apex, and a diastolic bruit along the left margin of the sternum. Pulmonary second sound well heard. Systolic thrill in the second left space and Gerhardt's dullness present. She is above the average in development and there is no history of rheumatic infection or indeed of any illness. $\mathrm{X}$-ray evidence positive.

Case 3.-Female, aged 19. Has had knowledge of her lesion for nine years and has never done any physical exercise. Well marked neurosis present. Complains of pains round the heart, dyspnœa, and palpitation on exertion. Of average development, she is said to have had anæmia in the past. Machinery murmur in the second left space with systolic thrill in the same situation. Pulmonary second sound reduplicated. Gerhardt's dullness present. Electrocardiogram shews low voltage in all three leads. Polygraph shews inequality of the pulses, the right being greater than the left. X-ray examination positive.

Case 4 (Fig. 3).-Male, aged 21. Of average development. Has known that he has had a cardiac abnormality for 11 years. Complains of pains round the heart on exertion. The pain is substernal, passes to the left scapula and to the left shoulder, from whence it passes down the inner side of the left arm. It is relieved by rest, and as the pain passes away a sensation of warmth comes to the regions where the pain has been felt. Machinery murmur in the second left space. Diffuse systolic thrill. Diastolic bruit present along the left sternal margin. Pulmonary second sound reduplicated. No cardiac enlargement detected. Inequality of the pulses shewn with the polygraph. Electrocardiogram physiological. X-ray examination shews dilatation of the pulmonary artery most marked in the oblique view, the frontal view shewing little more than fullness of the arc. Patient despite his handicap and a certain element of neurosis is in active work as a labourer. There is no history of rheumatism.

Case 5.-Male, aged 6. Lesion which was hitherto unsuspected, detected at the routine school examination at the age of 5 . Above the average in development, and no symptoms present. A long harsh systolic bruit is present and maximum in the second left space. Pulmonary second sound accentuated. X-ray shews prominence of the pulmonary arc. Patient has in addition facial asymmetry and epicanthic folds.

Case 6.-Female, aged 10. Of average development and no symptoms. Lesion first discovered at the routine school examination. Machinery bruit and systolic thrill in the second left interspace. Pulmonary second sound well heard. X-ray evidence positive.

Case 7 (Fig. 4).-Female, aged 12. Average size and no complaints. Lesion found at recent school examination and was apparently not detected at the school entrance examination. Machinery murmur present in the second left space without accompanying thrill. Pulmonary second sound accentuated and Gerhardt's dullness present. X-ray examination positive.

Case 8. - Female, aged 12. Rather undersized, and complains of precordial pain under any circumstances. Systolic bruit maximum in the second left space, and heard faintly at the apex. Pulmonary second sound accentuated. Pain has only been complained of since the detection of the lesion, two years ago, in an apparently healthy child at the routine school examination. Radiological examination typical picture of patent ductus.

Case 9.-Female, aged 6, of average size and no symptoms. Lesion was found at the routine school examination. Systolic bruit maximum in the second left 


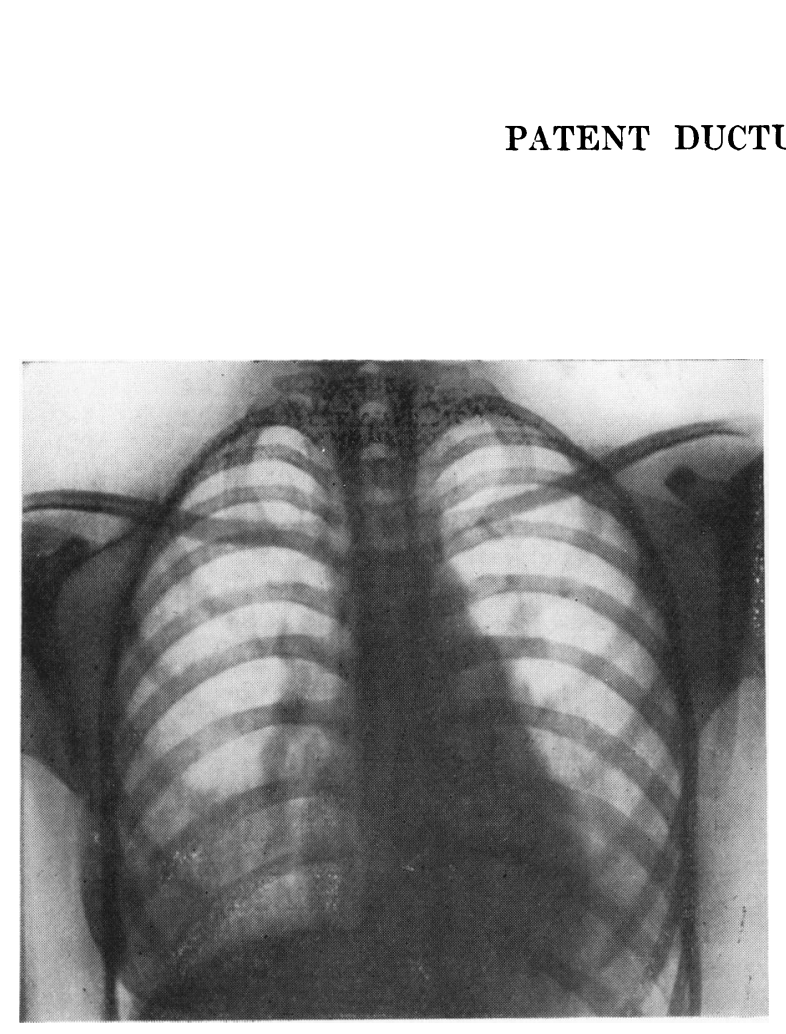

FIG. 1.-Case 1.

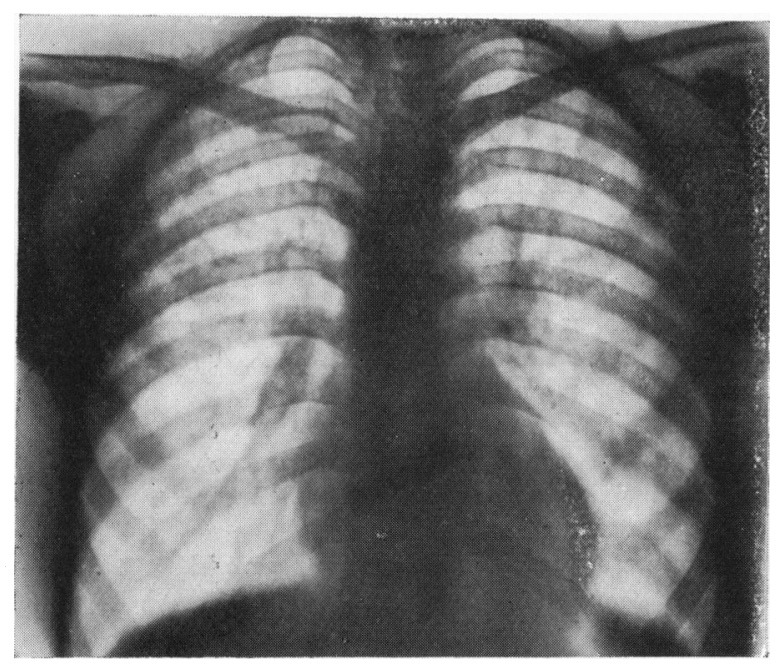

FIG. 3.- Case 4,
ARTERIOSUS

299

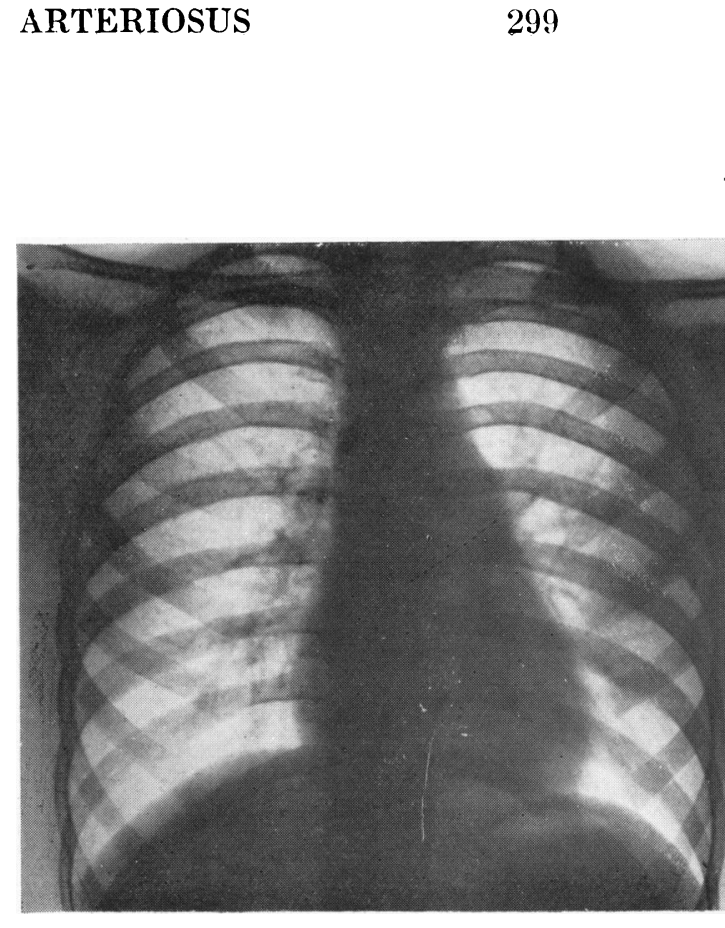

FIG, 2,-Case 2.

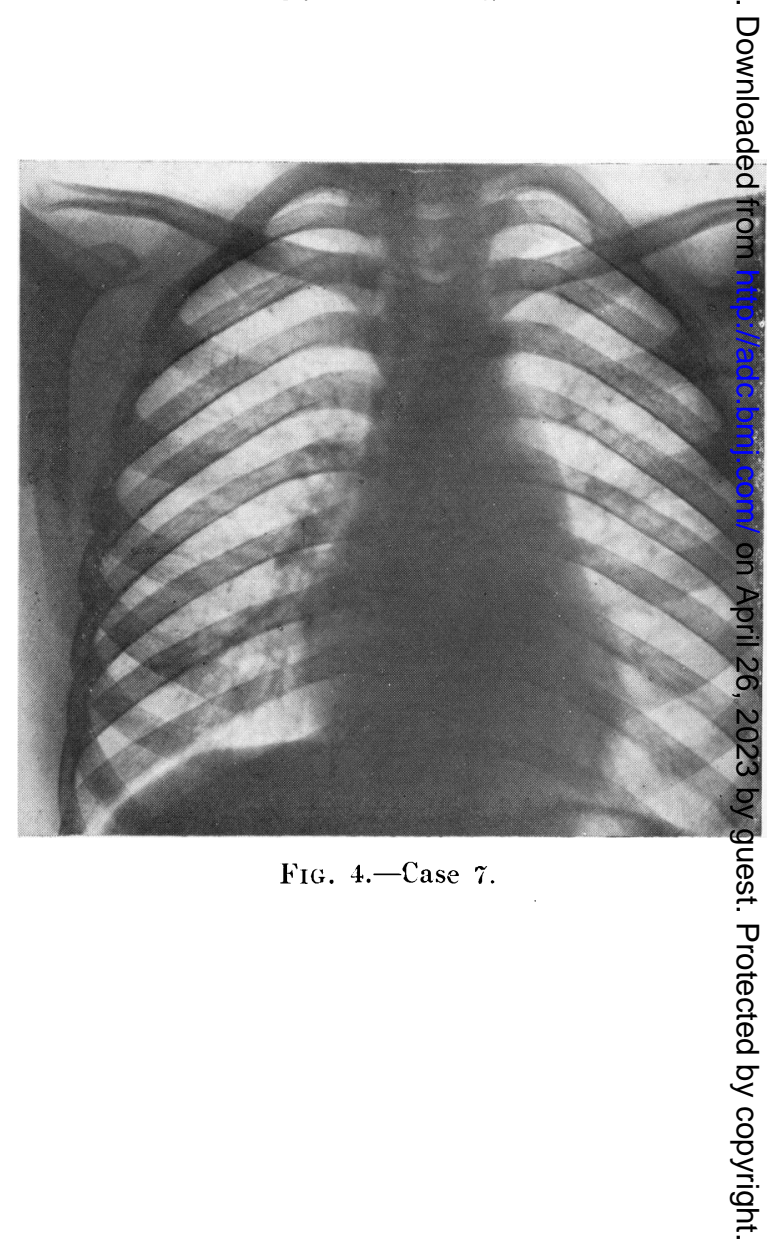


interspace, with accompanying systolic thrill. Pulmonary second sound well heard. Gerhardt's dullness present. X-ray shews prominent pulmonary arc.

Case 10.-Male, aged 12, of average size and no symptoms. Machinery murmur with accompanying systolic thrill in the second left space. Systolic bruit was audible at the apex. Pulmonary second sound accentuated. The lesion has been known of since measles four years ago. X-ray examination positive. Subsequently he developed an infective endocarditis with involvement of the aortic valves and the ductus. This case is recorded in more detail elsewhere ${ }^{10}$.

Case 11 (Fig. 5).-Male, aged 16. Above the average in size, and leading an active life with no symptoms. Lesion discovered on leaving school. No cardiac enlargement. Systolic murmur and thrill in the second left space. Pulmonary second sound accentuated, and Gerhardt's dullness present. X-ray shews a prominent left middle arc.

Case 12.-Male, aged 6. Above the average in size, and no symptoms. Lesion detected at the age of three during an intercurrent infection. Systolic bruit maximum in the third left space with systolic thrill best felt in the second left space. Diastolic bruit along the left sternal margin, and pulmonary second sound well heard. $\mathrm{X}$-ray examination positive.

Case 13 (Fig. 6).-Male, aged 15, with no complaints, and knowledge of the existence of the lesion since the school examination ten years ago. Systolic bruit and thrill maximum in the second left space. Pulmonary second sound well heard. Above average in development, leading an active life. X-ray examination positive.

Case 14.-Female, aged 9. Below average size but with no symptoms. Lesion found at the school entrance examination four years ago. Machinery murmur present in the second left interspace, but no thrill. Pulmonary second sound accentuated. X-ray evidence positive.

Case 15. - Female, aged 12. Above the average in size, but with no symptoms, and with knowledge of a cardiac abnormality for two years. Machinery murmur in the second left space with no thrill, and an accentuated pulmonary second sound. X-ray examination positive.

Gase 16.-Female, aged 7. No symptoms and above the average in development. The lesion was found recently at the school medical examination. Machinery murmur in the second left space with no thrill. Pulmonary second sound well heard. X-ray evidence positive.

Case 17 (Fig. 7).-Female, aged 13. Under average in size. The lesion was only recently found. Systolic bruit maximum in the third left space with a well heard pulmonary second sound. X-ray examination positive.

Case 18 (Fig. 8).-Female, aged 13, with no symptoms and above the average in development. She has known of the lesion for a year since it was found at the school examination. Systolic bruit and thrill in the second left interspace, with reduplication of the pulmonary second sound. Gerhardt's dullness present. X-ray evidence positive. Electrocardiogram physiological.

Case 19.-Female, aged 5. Rather small and thin and slightly below average. Heart lesion found at the routine school examination. No symptoms are present. She had two fits about two years ago in which she became blue. These were, however, not attributed to her heart. Machinery murmur in the second left space with accompanying systolic thrill. Gerhardt's dullness present. Pulmonary second sound reduplicated. X-ray examination positive.

Case 20.-Male, aged 12. Complains of vague pain in chest and some shortness of breath on exertion. His lesion was discovered when he had pneumonia at the age of 4. His brother apparently died of a congenital heart lesion with superadded infective endocarditis. No thrill present. A continuous murmur was best heard in the second left space with the subject erect. The systolic murmur was heard at the apex, in the left carotid, and very well in the left interscapular region behind. Pulsation poorly felt in the femoral vessels. He is above the average in development. $\mathrm{X}$-ray examination shews rounded prominence of pulmonary arc. 


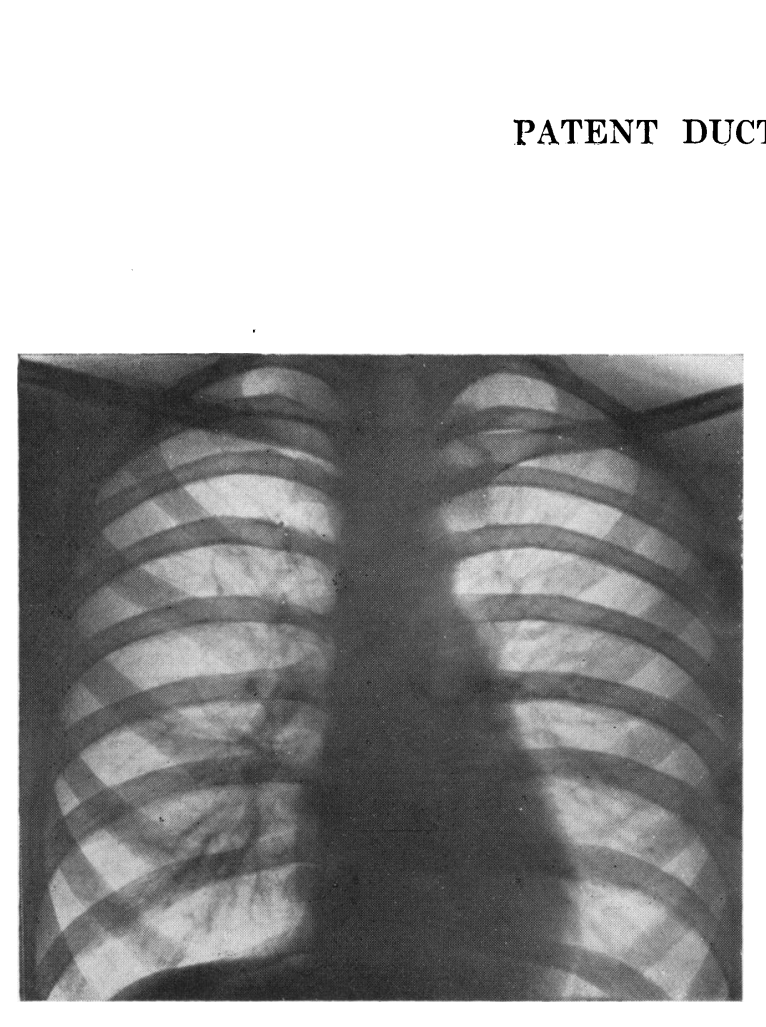

FIG, 5,-Case 11.

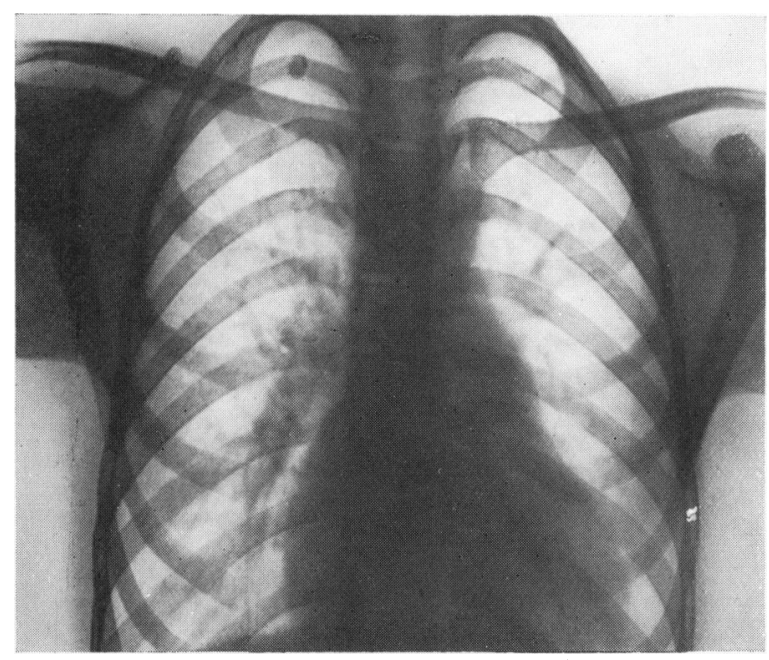

FIG. 7.-Case 17.

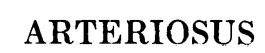

301

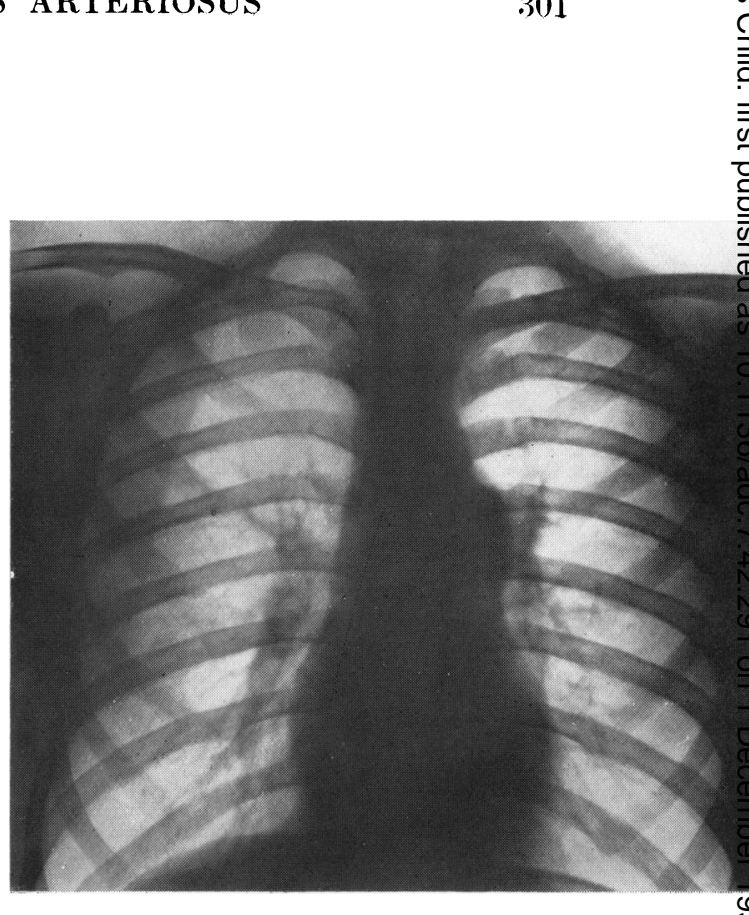

FIg. 6.-Case 13.

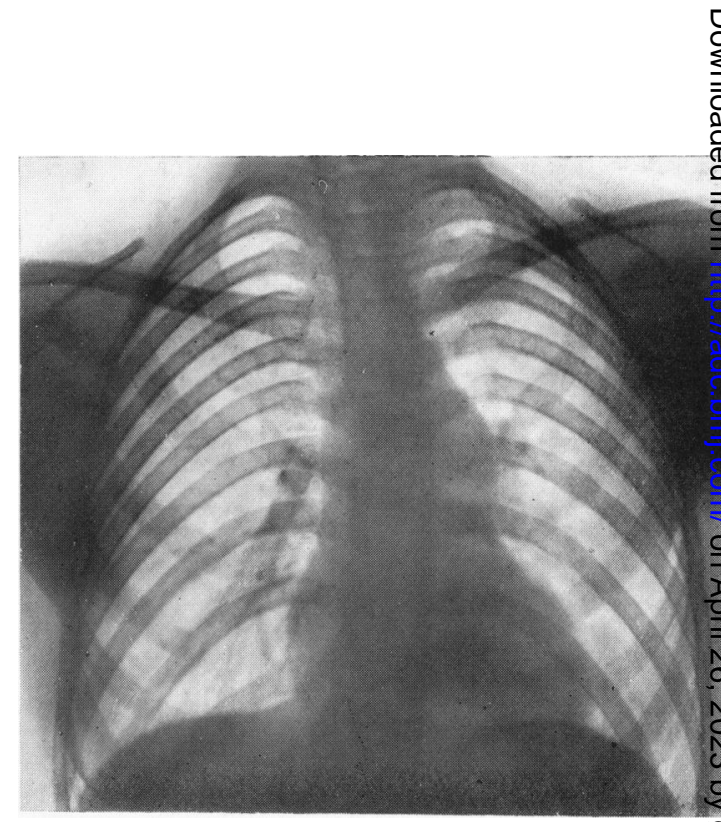

FIg. 8.-Case 18. 


\section{REFERENGES.}

1. Abbott, M., Modern Medicine, London, 1927, IV, 654.

2. Laubry, Ch., \& Pezzi, C., Maladies Congenitales du Coeur, Paris, 1921.

3. Perry, C. B., Arch. Dis. Childh., London, 1931, VI, 265.

4. Smith, S., Ibid., 1929, IV, 330.

5. Leech, C. B., Am. J. Dis. Child., Chicago, 1932, XLIII, 1086.

6. Gibson, A., Medical Press and Circular, London, 1906, i, 572.

7. Laubry, Ch., Nouveau Traite de Pathologie Interne, Paris, 1930, III.

8. Holman, E., Bull. Johns Hopkins Hosp., Baltimore, 1925, XXXVI, 61.

9. Lincoln, E. M., \& Spillman, R., Am. J. Dis. Child., Chicago, 1928, XXXV, 791.

10. Brown, J. W., Communication in press.

11. Eakin, W. W., Quoted by Abbott, Blumers Bedside Diagnosis, London, 1929, 476. 